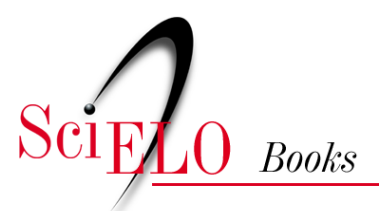

\title{
5. Estória do galo e do Candimba, de Leonardo Arroyo (1961) \\ contradições e renovação na literatura infantil brasileira
}

\author{
Vivianny Bessão de Assis
}

\section{SciELO Books / SciELO Livros / SciELO Libros}

ASSIS, V.B. Estória do galo e do Candimba, de Leonardo Arroyo (1961): contradições e renovação na literatura infantil brasileira. In: SILVA, M.C., and BERTOLETTI, E.N.M., orgs. Literatura, leitura e educação (online). Rio de Janeiro: EDUERJ, 2017, pp. 133-153. Pesquisa em educação/ Práticas de leitura e escrita series. ISBN 978-85-7511-497-1. Available from: doi: 10.7476/9788575114971.0006. Also available in ePUB from: http://books.scielo.org/id/5gg44/epub/silva-9788575114971.epub

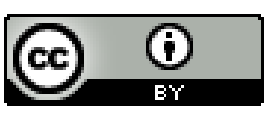

All the contents of this work, except where otherwise noted, is licensed under a Creative Commons Attribution 4.0 International license.

Todo o conteúdo deste trabalho, exceto quando houver ressalva, é publicado sob a licença Creative Commons Atribição 4.0.

Todo el contenido de esta obra, excepto donde se indique lo contrario, está bajo licencia de la licencia $\underline{\text { Creative Commons }}$ Reconocimento 4.0. 


\title{
5
}

\section{Estória do galo e do Candimba, de Leonardo Arroyo (1961): contradições e renovação na literatura infantil brasileira}

\author{
Vivianny Bessão de Assis
}

\section{Introdução}

Com o objetivo de contribuir para a produção de história, teoria e crítica específicas da literatura infantil e compreender o lugar ocupado por Leonardo Arroyo (I918-1985) em tudo isso, focalizamos, neste texto, ${ }^{\mathrm{I}}$ aspectos de sua produçáo escrita relacionada à produção de literatura infantil publicada na década de 1960, no Brasil.

Trata-se de uma pesquisa de abordagem histórica, que não visa a um julgamento de valor nem à assunção do ponto de vista defendido pelos sujeitos envolvidos. O objetivo deste texto é compreender as concretizaçóes e tematizaçóes (Mortatti, 2000) em relação à literatura infantil e juvenil, produzidas por um sujeito de outra época, influenciado pela produção sobre e de literatura infantil até então.

\footnotetext{
I Este texto resulta de pesquisa de doutorado (bolsa Capes), desenvolvida junta ao Programa de Pós-Graduação em Educação da Faculdade de Filosofia e Ciências, da Universidade Estadual Pau-

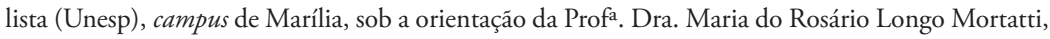
e vinculada ao Grupo de Pesquisa "História do Ensino de Língua e Literatura no Brasil" e ao Projeto Integrado de Pesquisa "História do Ensino de Língua e Literatura no Brasil” (PIPHELLB), ambos coordenados pela professora mencionada. O GPHELLB está em funcionamento desde 1994, cadastrado no diretório dos grupos de pesquisa do Brasil - CNPq e certificado pela Unesp.
} 
Assim, sem enquadrá-lo nos parâmetros do presente, buscamos compreender os aspectos envolvidos na produçáo de literatura infantil de Leonardo Arroyo, a partir de seu livro Estória do galo e do Candimba (196I), publicado na Coleção Verdes Anos, da Editora Melhoramentos (SP). Igualmente, procura-se compreender suas relaçóes com a época de produçáo, reconhecendo os sentidos que podem contribuir para o enfrentamento dos problemas do presente e construção do futuro da literatura infantil e juvenil em nosso país.

Com Estória do galo e do Candimba, Leonardo Arroyo (196I) contribui para a constituição de uma literatura infantil brasileira, produzida e publicada por uma editora que, à época, priorizava a publicação de livros voltados a crianças, empreendendo, de modo pioneiro, a difusão e a nacionalização de cartilhas, livros de leitura e de teorias educacionais, e investindo no aprimoramento gráfico e na ampliação do circuito de comercialização de livros.

Em 196I, ano em que o livro Estória do galo e do Candimba foi publicado, Manuel Bergströn Lourenço Filho estava à frente do trabalho editorial da Editora Melhoramentos (SP). Considerado especialista no assunto de leitura, literatura e crianças, emitia pareceres sobre livros de literatura infantil, participava como júri de concursos nessa área e dirigia a coleção "Biblioteca infantil", idealizada por Arnaldo de Oliveira Barreto, em I9I5, e coordenada por ele a partir de 1927 (Donato, 1990).

O período compreendido entre as décadas de 1940 e 1960 foi marcado pelo desenvolvimento da indústria editorial e pela expansão da escola brasileira. Desde então, aumenta-se a produçáo de livros para atender à demanda de necessidade de leitura pelos escolares. Foi nesse período também que, segundo Lajolo e Zilberman (1984), ocorreu a profissionalização do escritor e editor de livros de literatura infantil, momento marcado pela "[...] produção intensa e fabricação em série, respondendo de modo ati- 
vo à exigências crescentes do mercado consumidor em expansão" (p. 86). De acordo com essas autoras, os temas e espaços idealizados nos livros para crianças desse período eram sobretudo rurais, ao passo que a vida urbana foi ignorada. Assim, embora a produção de literatura infantil fosse quantitativamente maior, explorava "[...] filóes conhecidos e evitando a pesquisa renovada" (Idem, p. 87).

Esse padrão de temas e espaços mencionados pelas autoras também pode ser observado no livro Estória do galo e do Candim$b a$, de Leonardo Arroyo (I96I), pois a maior parte dos contos se passa no ambiente rural e na floresta. Até a década de 1960, as tematizaçôes que consolidaram o terceiro ciclo da literatura infantil brasileira foram a projeção de uma criança ideal, "[...] pautada pelas expectativas do adulto [...]" (Idem, p. I20). Diante disso, nos livros infantis, evidenciou-se a dependência da criança em relação aos mais velhos, "[...] a quem os mais frágeis devem se submeter para seu próprio bem" (Idem, p. I20).

No final da década de 1960, contudo, tem início, no Brasil, uma produção de vertente mais crítica e, com ela, tem-se a abertura de um novo ciclo na história de nossa literatura infantil. Nessa nova produção literária, é possível observar a inversão dos conteúdos típicos mencionados, por meio de uma tendência contestadora. Agora, as narrativas "[...] tematizam pobreza, miséria, injustiça, marginalidade [...]", autoritarismo, preconceito, entre outros (Idem, p. I40). Além disso, é possível observar uma mudança nos enredos e nas personagens, pois "[...] deixaram de ser exemplares do ponto de vista dos valores dominantes [...]” (Idem, p. I53).

Observa-se, portanto, que a década de 1960 trouxe várias mudanças de paradigma para a história da literatura infantil brasileira, pois, segundo Perrotti (1986), a produção nessa área sofreu uma "crise" que desencadeou uma nova tendência. Até 1960, Perrotti (I986) considera que tivemos o predomínio de um discur- 
so "utilitário" nos livros infantis e que, desse período em diante, teve início uma "[...] nova tendência discursiva dirigida a grupos infantis e juvenis no país [...]” (p. II), à qual denomina primado da estética. Surgem, então, escritores com uma "[...] consciência nova de seu papel social: reclamam a condição de artistas e desejam que suas obras sejam compreendidas enquanto objeto estético, abandonando, assim, o papel de moralistas ou 'pedagogos"” (Idem, ibidem).

Acreditamos que essa transposição de concepçôes em nossa literatura infantil pode ser observada nos contos do livro proposto, principalmente no plano do enredo, dos personagens e do conteúdo que se quer transmitir. Nele, observam-se diferentes concepções de literatura infantil, bem como sua relação com a época em que foi produzido.

Assim, com esta análise, buscamos compreender os seguintes aspectos: quais são as características da produção de literatura infantil de Leonardo Arroyo? O que mudou na literatura infantojuvenil das décadas de 1960 e 1970 em diante? Quais tendências se consolidaram? E quais delas foram historicamente abandonadas?

Para tal análise, recorremos aos conceito de "configuração textual", ${ }^{2}$ proposto por Mortatti (2000, p. 3I), que consiste em enfocar

[...] o conjunto de aspectos constitutivos de determinado texto, os quais se referem: às opções temático-conteudísticas (o quê?) e estruturais formais (como?), projetadas por um determinado sujeito (quem?), que se apresenta como autor de um discurso produzido de determinado ponto de vista e lugar social (de onde?) e momento histórico (quando?), movido por certas necessidades (por quê?) e propósitos (para quê), visando a determinado efeito

2 Para maiores informaçóes sobre o conceito de análise da configuração textual, ver Magnani (1997) e Mortatti (2000). 
em determinado tipo de leitor (para quem?) e logrando determinado tipo de circulação, utilização e repercussão.

\section{I Leonardo Arroyo: aspectos da formaçáo e da atuaçáo profissional}

O jornalista, escritor e historiador Leonardo Arroyo é neto de portugueses. Seus avós maternos vieram de Portugal entre i9io e I9II, fixando residência na cidade de Caieiras (SP). Arroyo nasceu na cidade de Sáo José do Rio Preto (SP), em 26 de fevereiro de I9I8, cidade na qual viveu boa parte de seu período escolar.

Entre 1938 e I940, concluiu o curso ginasial na cidade de Santos (SP) e, aos I8 anos, iniciou a carreira de jornalista no jornal $A$ Notícia, da cidade de São José do Rio Preto (SP). Entre os anos de I938 e I940, residiu na cidade de Santos (SP) e trabalhou no jornal A Tribuna, dessa cidade (Sant'ana, 2002, p. 27). Ainda nesse período, colaborou como redator da seção "Suplemento Literário" dos jornais A Tribuna (Santos, SP), Planalto (SP) e Gazeta Magazine (SP).

Em 1940, ingressou na Faculdade de Direito da Universidade de São Paulo, mas abandonou-a no segundo ano do curso para se dedicar ao jornalismo. Em 1942, passou a contribuir para a seção "Vida literária" dos jornais Folha da Manhã e Folha da Noite, antigos nomes da Folha de S. Paulo, permanecendo nesse periódico por mais de trinta anos.

Em virtude de seu prestígio social como escritor e jornalista no país, recebeu diversos prêmios e títulos, assumindo também alguns cargos no município de São Paulo (SP). Além de sua atuação como jornalista, Arroyo é autor de diversos livros de literatura, de literatura infantil, de abordagem histórica e de história e crítica literária. 
Leonardo Arroyo faleceu em I3 de agosto de 1985, aos 67 anos, no Hospital Sírio-Libanês, na cidade de São Paulo (SP), em decorrência de derrame cerebral e pneumonia.

\subsection{Apresentaçáo do livro 3}

Conforme mencionado, o livro em questáo foi publicado na Coleçáo "Verdes Anos", apresentada como "[...] narrativas que distraem e estimulam a inteligência das crianças através das peripécias de Pedro Malasartes, João Sabido, e de animais espertos, consagrados nas estórias ${ }^{4}$ de nosso folclore" (Melhoramentos, 1965, s.p.).

$\mathrm{Na}$ segunda orelha do livro, os contos são apresentados pela editora da seguinte maneira:

Êstes, pequenos amiguinhos, são exêmplos de desobediência e das graves conseqüências que ela gera. Espero, sinceramente, que nenhum de vocês corra tantos perigos para aprender a não desobedecer e não ser teimoso. Cuidado, que sempre o castigo espera os menininhos marotos que fazem má-criação e desobedecem (Melhoramentos, 1965 , s.p.).

O livro tem formato de $20,5 \mathrm{~cm} \times 17 \mathrm{~cm}$, contém 82 páginas e sete contos: "História do Galo"; "Didi, o mosquito"; "Dom Carretel e Dona Linha"; "O Ratinho teimoso"; "Candimba, a onça e a girafa"; "O poço vigiado"; e "A sabedoria do Candimba". De acordo com Coelho (2006), o "[...] termo 'Candimba' é de origem africana e significa 'coelho' [...]” (p. 417).

\footnotetext{
3 Não tivemos acesso à primeira edição desse livro, por isso os fragmentos aqui citados foram extraídos da terceira edição, publicada em 1965 .

4 Por se tratar de uma pesquisa histórica, mantivemos a ortografia original dos textos.
} 
Impressa em papel resistente e bastante colorida, a capa contém a ilustração dos principais personagens dos contos: uma girafa na lateral esquerda, um galo ao fundo, posicionado na lateral direita, e o coelho Candimba montado em uma onça. No centro da capa, consta o título em letras bastante destacadas. Essas ilustraçôes são de J. G. Villin e, no interior, constam, em média, duas ilustraçóes por conto nas cores preto e branco. Os quatro primeiros contos, "História do Galo", "Didi, o mosquito", "Dom Carretel e Dona Linha" e "O Ratinho teimoso", já haviam sido publicados em outro livro de literatura infantil de autoria de Arroyo, intitulado Histórias do galo (I950).5

Consideramos, portanto, que Estórias do galo e do Candimba é uma versão ampliada do outro livro, com a inserção de três novos contos que, segundo Coelho (2006), foram inspirados no folclore africano, recolhidos em uma comunidade rural no interior do estado do Maranhão pelo Professor Otávio da Costa Eduardo.

A obra teve quatro ediçóes diferentes, todas publicadas pela Melhoramentos (SP): a primeira em I96I; a terceira em 1965; e a quarta em 197I. Até o momento, não localizamos informaçóes acerca do ano em que a segunda ediçáo foi publicada, nem foi possível recuperarmos exemplares de qualquer uma das ediçóes mencionadas. $\mathrm{O}$ acesso ao exemplar da terceira edição, ora apresentado neste texto, foi obtido mediante consulta ao acervo da coleção de obras raras da Biblioteca Mário de Andrade, na cidade de São Paulo.

5 Para maiores informaçóes sobre o livro, ver artigo nosso intitulado "História do galo (I950), de Leonardo Arroyo, e um modelo de formação de leitor”, publicado na revista Interfaces da Educação (2015). 


\subsection{Aspectos do conteúdo}

Há um intervalo de II anos entre a produção escrita dos quatro primeiros contos, publicados no livro História do galo, em I950, e dos três últimos, que são inéditos. Esse intervalo gerou algumas mudanças no estilo de escrita de Arroyo, nas características dos personagens e no conteúdo dos contos. Assim, para se observarem essas mudanças, os contos sáo apresentados em dois conjuntos, respeitando-se esse intervalo. O primeiro conjunto é composto por "História do galo", "Didi, o mosquito", "Dom Carretel e Dona Linha" e "O Ratinho teimoso". O segundo conjunto, por sua vez, reúne: "Candimba, a onça e a girafa", "O poço vigiado" e "A sabedoria do Candimba".

O conto "História do galo" se passa no "país do galinheiro", onde galinhas, galos, patos e marrecos viviam satisfeitos. Os personagens principais são o Galo, a Franguinha Branca, o Marreco Preto e um homem e uma mulher que visitavam o galinheiro algumas vezes ao dia. A única interrupção na rotina do galinheiro era quando, de tempos em tempos, a mulher dizia ao homem a seguinte frase: "Aquela está boa". Após dizer isso, "alguém desaparecia" (Arroyo, 1965, p. 8).

Os animais eram conformados com essa rotina, até a chegada de um galo diferente no galinheiro, que, embora bem recebido pelos outros animais, comportava-se de modo "egoísta" e "arruaceiro":

Ao ver o milho espalhado por todos os lados o novo habitante entendeu que tudo deveria ser somente seu. Começou a distribuir bicadas a torto e a direito, gritando: - Saiam todos! Deixem-me comer sossegado! [...] — Quem ousa protestar? Quero saber para dar-lhe uma lição! (Arroyo, I965, p. I0). 
Devido a esse comportamento do novato, os demais habitantes do galinheiro reuniram-se em assembleia, e Marreco Preto teve uma ideia para deixar o Galo irritado a ponto de chamar a atenção dos humanos e "desaparecer" também. Desde esse dia, a paz voltou a reinar no galinheiro: "[...] os habitantes se respeitavam, todo mundo comia em paz, sem brigas, sem algazarra” (Arroyo, 1965, p. I8).

No segundo conto, "Didi, o mosquito", a história se passa no "país da cavalariça". Os personagens principais são Didi, Dom Mosquito, Dona Mosquito (pais de Didi) e um mosquito velho e "estrangeiro" que aparecera por lá. Didi era um mosquito teimoso, barulhento, um "diabinho em pessoa", que não ouvia os conselhos dos pais nem ia à escola: "Dona Mosquito ralhava com êle, Dom Mosquito vivia a dar-lhe bons conselhos, mas o travêsso não levava a sério o que êle dizia" (idem, p. I9). Certo dia, Didi encontrou o mosquito velho e "estrangeiro", que estava de passagem e seguia para o "país das casas". Didi, então, decidiu fugir com ele para esse novo lugar. Ao chegar lá, contudo, Didi desobedeceu ao mosquito velho, ao picar o nariz de um homem que dormia. Ao acordar, o homem encheu a casa de inseticida, Didi ficou "tonto" e quase foi apanhado. Entáo, com medo e saudade de casa, pediu ao mosquito velho que o levasse de volta para o "país da cavalariça". Didi arrependeu-se e desde "[...] êsse dia foi-se transformando. Tornou-se, afinal, obediente e ia à escola todos os dias. Ninguém mais o vira fazer travessuras" (Idem, p. 33).

No terceiro conto, "Dom Carretel e Dona Linha", a história se passa no "país do cêsto de costura" e os personagens principais são Dom Carretel, Dona Linha, tia Zefa e Dom Botão Preto, "filósofo" do país. Dom Carretel era orgulhoso, soberbo e vaidoso, enquanto Dona Linha era elegante, muito branca e sentia-se triste com os desaforos de Dom Carretel, que vivia reclamando por ter de "carregar" Dona Linha para todo canto. 
Dom Carretel não aceitava o "destino" de carregar Dona Linha, pois queria "liberdade". Após um dia inteiro de trabalho, tia Zefa deixou Dom Carretel em cima de uma cadeira, ele escorregou e saiu rolando pela sala de modo desgovernado, até se desvencilhar totalmente de Dona Linha. Dom Carretel, então, sentiu-se com muito medo e sozinho. Assim, somente após ter sido encontrado por tia Zefa e enrolado novamente em Dona Linha, voltou a se sentir bem: "Desde êsse dia, Dom Carretel vive em paz no país do cêsto de costura. E gosta muito de Dona Linha [...]" (idem, p. 40).

No quarto e último conto desse conjunto, "O ratinho teimoso", a história se passa na despensa da cozinha de um "velho casal". As personagens principais são Dom Rato, Dona Rata, Ratinho e o Gato Amarelo. Dom Rato era muito cauteloso e experiente, e "[...] não permitia estragos no país da despensa. Não deixava que Dona Rata e Ratinho roessem os sacos de mantimentos apenas pelo prazer de destruir nem que se atirassem às lingüiças e aos queijos de ralar, por esganaçáo" (Idem, p. 4I).

Ratinho, por sua vez, era desobediente, teimoso e esganado, e vivia visitando o local às escondidas. A chegada de um novo queijo deixou Ratinho com muita fome e com vontade de desobedecer. Um dia, enquanto seus pais dormiam, Ratinho foi até a despensa e começou a roer o queijo. E roeu tanto que fez um buraco no queijo e decidiu dormir lá dentro. Quando acordou, foi surpreendido pelo Gato Amarelo. Depois de sentir muito medo, Ratinho aproveitou um minuto de sono do Gato Amarelo para escapar e voltar para casa. Desse dia em diante, nunca mais desobedeceu.

No segundo conjunto de contos inéditos, constam: "Candimba, a onça e a girafa", "O poço vigiado" e "A sabedoria do Candimba”. 
No primeiro conto, Candimba quer se casar com a dona Girafa, mas ela já estava de casamento marcado com o camarada Onça. Candimba, então, se irrita e diz que dona Girafa estava fazendo uma péssima escolha, pois a camarada Onça era o seu "cavalo". Dona Girafa não acreditou naquela conversa e logo dispensou Candimba. No entanto, no dia do casamento, "[...] o coelho pegou a sua sela, a manta, as esporas e os estribos, e escolheu um lugar perto da estrada que levava à casa da dona Girafa" (Idem, p. 56). Sentou-se perto de onde todos passariam, mas disse que não iria ao casamento, pois estava com dor dente. Quando o noivo passou por ali, contou-lhe essa história e, com pena do coelho, o noivo ofereceu-lhe uma carona em seu lombo.

- Oh! o camarada Onça é muito gentil! Mas eu não posso ir ao casamento e deixar a minha manta aqui na estrada.

- Ôra Candimba, eu faço questão que você vá, bote a manta aqui em cima de mim. [...]

- Assim eu caio, choramingou o coelho, preciso amarrar a manta e colocar a sela. Ai, ai, meu dente (Arroyo, 1965, p. 57).

Assim, enganando o camarada Onça com seu discurso de doente, Candimba conseguiu convencê-lo a vestir todos os itens da montaria, aparecendo no casamento com seu "cavalo", como havia afirmado à dona Girafa. Após esse episódio, dona Girafa desiste do casamento e pede vingança. $\mathrm{O}$ camarada Onça procura um jeito de "pegar" Candimba. Então, Dom Jabuti chega com a informação de que Candimba vinha, toda noite, até a beira do rio para tomar água. A pedido do camarada Onça, Dom Jabuti cobre-se de cera e esconde-se perto de um monte de pedras. Assim, ao tocar "naquele vulto", Candimba fica preso e é pego pelo Onça. Candimba, então, pede desculpas, mas engana o camarada Onça mais uma vez, dizen- 
do que tinha uma recompensa maior: um boi bem gordo no pasto. Ao "buscar" a recompensa, o coelho foge sem deixar vestígio.

O segundo conto, "O poço vigiado", narra a história de um poço construído pelos animais da floresta para evitar a longa distância diária até o rio. Candimba foi o único entre os animais que não ajudou em sua construçáo, porque dizia estar com dor de dente. Diante disso, todos decidiram que Candimba não tomaria a água do poço. Mas, mesmo assim, todo dia à noite, Candimba enchia suas caçapas com água sem que ninguém o visse. Após muitas tentativas de outros animais em desmascará-lo, o camarada Onça consegue flagrá-lo e contrata o compadre Urubu para vigiá-lo. No entanto, Candimba também o engana, jogando areia em seus olhos e fugindo mais uma vez.

No último conto, "A sabedoria de Candimba", o coelho decide construir uma "tapagem" à beira do rio para pescar peixes. O camarada Onça, por sua vez, não conseguia pegá-los e estava com fome, então decidiu perguntar a Candimba como ele fazia. O coelho mostrou orgulhosamente sua construção, e o camarada Onça decidiu tirar vantagem da situação por meio de sua força. Tomou para si a construção, ficando com os peixes maiores e entregando os menores a Candimba. Um dia, Candimba teve uma ideia: correu para dentro da mata e começou a gritar, dizendo que precisava amarrar-se às árvores porque uma forte tempestade se aproximava. Assustado com os gritos do coelho, o camarada Onça pediu para ser amarrado primeiro. Após três dias, foi solto pelo mestre Macaco e escondeu-se na casa de Candimba, a fim de pegá-lo. Candimba, no entanto, voltou a enganá-lo e se salvou.

Em todos os contos, as ilustraçóes apresentam um caráter elucidativo e/ou referencial, ilustrando o poder de verdade da fantasia no texto literário. Atuam, portanto, como uma síntese do texto escrito, e não como uma extensão da leitura. 


\subsection{Personagens}

O coelho Candimba é o único personagem que transita entre os contos, fazendo-se presente em três do total de sete. Por isso, é possível observar um padráo de continuidade entre alguns contos, visto que as histórias se passam no mesmo ambiente - a floresta e na companhia e/ou no confronto dos mesmos animais. Curioso, nesse aspecto, é o fato de o personagem Galo aparecer apenas no conto intitulado "Histórias do Galo", já que também compóe o título do livro.

Outro aspecto digno de nota em relação aos personagens é que são todos animais e, assim como nas fábulas, apresentam características humanas, como sentimentos e comportamentos inteligíveis. A única exceção a esse padrão é o conto "Dom Carretel e Dona Linha”, em que os personagens são objetos.

No primeiro conjunto de contos, a maior parte dos personagens centrais está em idade infantil, portanto assemelha-se às crianças. Essa condiçáo é marcada por atitudes como mostrar-se egoísta, manifestar gula e teimosia, ser desobediente, não querer ir à escola, entre outras. De modo geral, os personagens infantis desobedecem a uma orientação dos mais velhos e são "castigados". Em seguida, arrependem-se e readquirem o equilíbrio. $\mathrm{O}$ estado final ${ }^{6}$ desses contos é apresentado, portanto, com a correção que vem dos personagens adultos ou com o pedido de desculpas dos personagens infantis. Assim, comportamentos como ser obediente, saber viver em comunidade, compartilhar o alimento sem desperdício, não demonstrar gula, sentir gratidão, não ter preguiça e não se arriscar são atitudes valorizadas na criança que aprende a lição no final dos contos. Nesse contexto, os animais em idade

6 Segundo Yves Reuter (2002), trata-se do modelo de narrativa composto por cinco estados de transformação: estado inicial; complicação ou força perturbadora; dinâmica; resolução ou força equilibradora; e estado final. 
infantil legitimam a imagem da criança em fase de desenvolvimento, que necessita da orientaçáo dos adultos. A literatura infantil, portanto, cumpre seu papel de "instrumento de educaçáo" (Lourenço Filho, 1943), como apregoado entre os livros publicados naquele período.

Nos quatros primeiros contos, os modelos narrativos se organizam numa sequência de eventos que se desenrolam em busca de um equilíbrio final para o desequilíbrio provocado. Desse modo, a narrativa centra-se na ação que busca a resolução do problema e na "lição" que pretende transmitir.

Em oposição a essa dinâmica, estão os três últimos contos, nos quais Candimba é o personagem principal: "Candimba, a onça e a girafa", "O poço vigiado" e "A sabedoria de Candimba". Nesses casos, a mensagem ou o instrumento de educação são outros: a esperteza e a inteligência, com frequência associadas à capacidade de enganar e de tirar vantagem do outro. Esses aspectos podem ser observados, principalmente, nos dois primeiros contos desse conjunto.

No segundo conjunto, não há diferenciação entre as idades dos personagens, portanto não há personagens adultos sustentando as açôes das crianças, ora para castigá-las, ora para auxiliá-las a sair de algum problema. Neles, o estado final não visa ao retorno do equilíbrio que havia no estado inicial, visto que o objetivo é que Candimba saia "ileso" às situaçóes de conflito provocadas, por ele mesmo, no início da narrativa. Desse modo, o equilíbrio ou a resolução do conflito decorrem de um desfecho inusitado, em geral representado pela "fuga" ou o "escape" da situação, conforme se observa nos seguintes fragmentos: 
Conto "Candimba, a onça e a girafa":

- Então, vá buscar o boi que eu espero aqui junto com o Jabuti. Candimba saltou e foi embora. O camarada Onça, conversando com o dom Jabuti, até hoje está esperando pelo esperto coelho. Está claro que Candimba não voltou com boi nenhum! (Arroyo, I965, p. 63).

Conto "O poço vigiado":

E levantou a voz pela terceira vez:

- Eh, minha casa!

E o camarada Onça escondido perto da porta (ai, que tonto o camarada Onça) respondeu numa voz grossa:

- U...U...U...

Candimba deu uma gargalhada enorme.

— Essa é boa! Onde se viu casa falar?

E correu para longe, a tôda velocidade! (idem, p. 82)

Outro aspecto da dinâmica desse conjunto de contos é que a trama se desenvolve até que Candimba consiga realizar o que disse no início da narrativa:

- Olha lá dona Girafa. Você recusou casar comigo, mas vai casar com meu cavalo!

- O que você disse Candimba? [...]

— Então não sabe? [...]

- Pois eu virei ao casamento montado no camarada Onça, que é meu cavalo! (Arroyo, 1965, p. 55)

O conto "A sabedoria de Candimba" é o único desse conjunto em que a esperteza do coelho é utilizada para livrá-lo de uma situação não provocada por ele. Sua inteligência o ajudou a sair 
de um conflito em que estava sendo explorado pelo "camarada Onça".

— [camarada Onça] Quem vai dividir os peixes de hoje em diante sou eu! [...]

O coelho ficou amedrontado, mas, no íntimo, jurou vingar-se do camarada Onça na primeira oportunidade (Arroyo, 1965, p. 74).

A narração se assemelha à tradição oral. Esse recurso garante uma linguagem que prende a atenção do leitor, pois intercala a narração com os diálogos entre os contadores e os ouvintes das histórias. Em todos os contos, o narrador é um observador objetivo, não conhece o que se passa na mente dos personagens e apenas relata os fatos, por meio da descrição, da ação dos personagens e dos diálogos (Reuter, 2002).

\subsection{Espaço e tempo}

A representação dos espaços é feita por ambientes comuns à literatura infantil, os quais lembram ambientes rurais, tais como: floresta, galinheiro, cesto de costura, estábulo de cavalos e despensa de uma cozinha. Esses ambientes conferem verossimilhança às histórias e permitem ao leitor identificar-se com o espaço representado.

As narrativas se passam em curtos espaços de tempo, configurando os eventos numa sequência cronológica e linear. Desse modo, não há complexidade no encadeamento das ações, podendo ser mensuradas por meio da alternância de dias e noites. 


\subsection{Momento histórico de produçáo}

Os anos I950, em linhas gerais, fomentaram o início de um processo de industrialização nacional, promovida pela abertura ao capital externo para investimento. Essa influência estrangeira decorreu principalmente do alinhamento político que o Brasil adotou junto a Inglaterra, França, Estados Unidos e Uniāo Soviética, contra os regimes nazifacistas da Alemanha, da Itália e do Japão (Lajolo e Zilberman, I986).

A década de 1960 foi um momento cultural eminentemente crítico e polêmico, com o endurecimento do regime a partir de 1964. A literatura para crianças e jovens não permaneceu imune às transformaçóes ocorridas na sociedade brasileira, e a produção de textos literários provocou a formação de novos padróes de desenvolvimento, com personagens mais críticos. Observam-se mudanças significativas nos sete contos que integram Estória do galo e do Candimba, principalmente quanto às características dos personagens e ao conteúdo das histórias.

Os primeiros quatro contos, publicados inicialmente em I950, apresentavam-se ligados à tradição que se instalara no gênero, articulando-se com as concepçóes educacionais, editoriais e psicológicas do período, que, de acordo com Lajolo e Zilberman (I986), valorizavam a produção de modelos de comportamento nas histórias infantis: "[...] atitudes ideais e crianças exemplares" (p. I29). E acrescentam:

[...] os autores dos anos 40 e 50 amansam o comportamento dos protagonistas, agora mais domésticos e dependentes, preocupados em demonstrar sua correçáo perante os adultos [...]. As crianças passam por várias aventuras, geralmente seguidas de sentimentos de culpa [...] (Idem, pp. I30-I). 
Seguindo essa tendência de produção literária, a criança leitora, para Arroyo, era considerada pela ótica da psicologia e da educação, o que acabava por limitar as opçôes literárias e estéticas. Assim, no livro em questáo, os aspectos desse projeto de educação são concretizados, e a formação pretendida se aproxima da transmissão de normas, realçando a égide familiar, o bom comportamento, o ensino e o trabalho.

Nos três últimos contos, todavia, há uma mudança de paradigma em relação aos demais apresentados, pois Candimba assume uma tendência contestadora e irreverente na literatura infantil, táo diferente dos demais, o que gera certa estranheza e reaçóes polêmicas do ponto de vista social. Com o personagem Candimba, sobressai-se a ideia de fazer da leitura de literatura infantil um elemento de formação estética, e não de difusão de civismo e patriotismo, de linguagem modelar e de ensino. Assim como Arroyo, muitos autores e obras passaram a representar "[...] a criança capaz de rebeldia e de ruptura com a normatizaçáo do mundo dos adultos. Enfraquece, assim, a velha prática de representar nos livros infantojuvenis apenas situaçóes não problemáticas" (Luft, 20IO, p. II3).

Perrotti (1986), contudo, afirma que o desejo de renovação resultou, em muitos casos, num conjunto de obras "equivocadas", reunidas sob o título "o utilitarismo às avessas" (p. 23), pois, embora fossem renovadas pelo fato de acolherem o ponto de vista da criança e não mais do adulto, sua dinâmica procurava impor um novo comportamento ao leitor. Esse fato criava novamente outro "[...] modelo de criança ideal [...]", o qual deveria ser seguido (idem, p. I23). No livro de Arroyo, as mudanças na concepção de literatura infantil saltam aos olhos ao se levar em conta o intervalo de II anos da publicação de um conjunto de contos para o outro.

É possível observar que esse esforço de renovação em Estória do galo e do Candimba também levou ao "utilitarismo às avessas" 
diagnosticado por Perrotti. De um lado, os personagens infantis são representados como aqueles que "erram" sempre e precisam hierarquicamente aprender a "lição" com os adultos. De outro lado, o personagem Candimba pode fazer tudo o que quiser, pois o importante é que sua vontade seja satisfeita. Desse modo, os contos desse livro apresentam oposiçóes drásticas entre si, quebrando o encadeamento e o equilíbrio, pois os campos estáo muito polarizados: nada posso sozinho (sem a companhia do adulto) versus tudo posso (pois somente a minha vontade importa).

Perrotti (1986) indaga: seriam os "[...] critérios estéticos suficientes para a apreensão do problema? Se forem, há ainda uma questáo que fica no ar: que estética? [...]" (p. 20). Reconhecer as reais tendências da literatura para crianças e jovens, bem como os modismos de determinada época, não é tarefa fácil, principalmente quando a cultura e a obra de arte tornaram-se comprometidas com o mercado.

Em Estória do galo e do Candimba (196I), as diferentes concepçôes de literatura infantil evidenciam o momento de "crise" de uma época e as mudanças que se consolidaram nas décadas de I960 e 1970 em diante. Não se pode perder de vista, ainda, que o valor de uma obra literária oscila com o tempo, dependendo dos sujeitos - autorizados - que a julgam. Assim, os sujeitos e as instituiçôes envolvidas na "cadeia produtiva" da literatura infantil - representada por autores, editoras, educadores, pesquisadores e o leitor previsto - interferem nas concepçóes de "boa literatura" que o gênero vem assumindo historicamente (Mortatti, 2008).

\section{Consideraçóes finais}

Por meio do livro analisado, é possível compreender aspectos importantes da produção de literatura infantil de Leonardo Arroyo, em consonância com as concepçóes desse gênero literário 
após meados do século XX no Brasil. Também foi possível compreender alguns aspectos de sua atuação profissional, pois, como escritor para crianças, contribuiu para a literatura infantil com esse livro, que teve quatro ediçóes em um período de II anos.

A análise histórica de Estória do galo e do Candimba permite-nos olhar do ponto de vista do presente, reconhecendo os lugares de origem de nossa literatura infantil, bem como compreendendo as relaçóes de cultura e poder que a mediaram e permanecem até os dias atuais.

Esse livro, portanto, sintetiza as contradiçôes entre a continuidade de uma tradição e o desejo de renovação cultural na infância brasileira. Trata-se de uma obra que permaneceu no tempo, impulsionada, talvez, por suas próprias contradiçóes e pelas contradiçóes de sua época, formando diferentes leitores, reescrevendo as “dobras" da literatura para a infância e para uma educação literária em nosso país.

\section{Referências}

ARROYO, Leonardo. Estória do galo e do Candimba. ed. São Paulo: Melhoramentos, I965.

DONATO, Hernâni. Ioo anos de Melhoramentos: I890-1990. São Paulo: Melhoramentos, 1990 .

LAJOLO, Marisa e ZILBERMAN, Regina. Literatura infantil brasileira: história \& histórias. São Paulo: Ática, 1984.

. Um Brasil para crianças: para conhecer a literatura infantil brasileira: história, autores e texto. São Paulo: Global, 1986.

LOURENÇO FILHO, Manuel Bergstrom. "Como aperfeiçoar a literatura infantil”. Revista Brasileira, Rio de Janeiro, v. 3, n. 7, pp. I46-69, 1943.

LUFT, Gabriela. "A literatura juvenil brasileira no início do século XXI: autores, obras e tendências". Estudos de Literatura Brasileira Contemporânea, n. 36. Brasília, jul./dez. 20IO, pp. III-30. 
MORTATTI, Maria do Rosário Longo. Os sentidos da alfabetização (São Paulo, I876-I994). São Paulo: Unesp; Brasília: Mec/Inep/Comped, 2000. . "Literatura infantil e/ou juvenil: a 'prima pobre' da pesquisa em Letras?". Revista Guavira Letras, Três Lagoas, n. 6, pp. 43-52, 3I mar. 2008.

PERROTTI, Edmir. O texto sedutor na literatura infantil. São Paulo: Ícone, 1986.

REUTER, Yves. A análise da narrativa: o texto, a ficção e a narração. Trad. Mario Pontes. Rio de Janeiro: Difel, 2002. 